\title{
SENSING OF VOLATILE ORGANIC COMPOUNDS IN INDOOR ATMOSPHERE AND CONFINED AREAS OF INDUSTRIAL ENVIRONMENTS
}

\author{
L.I.B. SILVA ${ }^{1,2^{\star}}$ \\ T.A.P. ROCHA-SANTOS ${ }^{2}$ \\ A.C. DUARTE ${ }^{1}$
}

Received: $26 / 12 / 07$

Accepted: 18/03/08

\author{
${ }^{1}$ CESAM \& Department of Chemistry, University of Aveiro, \\ 3810-193 Aveiro, Portugal \\ ${ }^{2}$ Instituto Piaget, Campus Académico de Viseu, \\ Estrada do Alto do Gaio, Lordosa, 3515-776 Viseu, Portugal
}

*to whom all correspondence should be addressed: e-mail: lisilva@ua.pt

\begin{abstract}
A chemical vapour sensor working with a monochromatic light source and based on optical fibre coated with a thin siloxane polymer film has been developed for in situ monitoring of volatile organic compounds, such as ethylbenzene, xylene (o-xylene), heptane, octane, chloroform, carbon tetrachloride, ethanol and butanol in indoor atmosphere and confined areas of industrial environments. The sensor consists on a monomode optical fibre with an end surface coated with a thin polymeric film by dip-coating technique. The light source utilized was a stabilized laser diode at $1550 \mathrm{~nm}$ and the light power changes were measured with a photodiode. The sensor was tested for different VOCs and for different individual concentrations regarding stability, sensitivity, repeatability and reversibility of the analytical signal. The response and desorption time have been found to be 30 seconds and good reproducibility and accuracy have been also obtained. Finally, the analytical performance of the developed sensor was also evaluated and found adequate for actual monitoring on indoor atmospheres.
\end{abstract}

KEYWORDS: gas sensor, optical fibre sensor, air monitoring, VOCs sensor

\section{INTRODUCTION}

Volatile Organic Compounds (VOCs) are commonly found in the environment, indoor air, and workplaces and can be present in a large variety of consumer products; however concentrations of many VOCs are consistently higher indoors than outdoors (EPA, 2007). These compounds derive from numerous activities such as printing, surface cleaning, varnishes, inks and adhesives, pharmaceutical products manufacturing, industrial organic solvents uses, fuels use and other more anthropogenic and/or natural causes (Turner et al., 2006; Dubray and Vanderschuren, 2004). Human exposure to these substances could occur through skin contact, inhalation and ingestion and even at a low concentration these compounds could present human healthy risks due its potential carcinogenic, neurotoxic, genotoxic and mutagenic activity. Therefore the monitoring of VOCs in confined working areas, assuring an indoor air quality (IAQ) acceptable becomes a very relevant issue for a healthy environment. Chemical sensors are particularly valuable for environment monitoring since they can provide either continuous or near-continuous information concerning concentration monitoring of chemical pollutants. Optical fibre sensors show excellent advantages for analytical proposes, namely, electromagnetic immunity, remote sensing, online monitoring, low-cost, high durability and stability (Campbell,1997). Optical fibre sensing technologies also provide the basis for measurements with high sensitivity and accuracy of a large variety of toxic compounds. Furthermore, optical fibre sensors can be used for fast and safe detection in environments with high inflammability risk and inaccessible areas, such as in high temperature or radiation environments.

In recent years, many optical fibre sensors for organic vapours detection have been reported based on optical fibre technology (Zimmermann et al., 1997; Kondratowicz et al., 2001; 
Abdelmalek et al.,1999; Abdelghani et al., 1997a; Abdelghani et al., 2001; Abdelghani et al., 1997b; Horrillo et al., 2004; Bariáin et al., 2001; Bariáin et al., 2003; Bariáin et al., 2005; Elosúa et al., 2006). Optical fibre sensors based on polymer-cladding are a very promising tool concerning VOCs detection, due to its simplicity and sensitivity. The sensing principle underline this sensor type consists basically on measurements of the changes in the polymeric coatings proprieties when an analyte (VOC) is present. The amount of VOC absorbed into polymer cladding is proportional to the ambient concentration of the VOC. Polymer based sensor can be applied to several volatile and semi-volatile organic compounds monitoring, as well for industrial solvents, toxic substances, water vapour, ammonia and some explosives detection. These sensors show a high potential for in situ measurements, in a continuous mode operation besides showing a very short analytical time.

This work aimed at the development of a new and compact design for an optical fibre sensor for monitoring VOCs in confined environments.

\section{EXPERIMENTAL SET-UP AND MATERIALS}

Analytical details and set up of optical fibre based sensor

Figure 1 shows a schematic diagram of the sensor configuration. The experimental set-up is generically constituted by a light source (a laser diode $(1 \mathrm{~mW}, \lambda=1550 \mathrm{~nm})$ from Oz Optics), a photodetector also from Oz Optics and an optical fibre (single-mode optical fibre pigtail, core and cladding diameters of 9 and $125 \mu \mathrm{m}$, respectively) sensitized with a thin polymeric film of dimethylpolysiloxane (DMPSV, Sigma Aldrich). The exposure of the polymeric film to organic volatile compound vapours causes a change in its refractive index leading to a variation of the light power. The intensity of the light power variation was measured by the optical detector, and data acquisition was performed by home made software. A directional coupler 50:50 was used and a small length of the optical fibre was mechanically uncladded and then cleaved on a length of $15.0 \mathrm{~mm}$ with a Cleaver V6 (from Future Instrument) precision fibre cleaver. This naked optical fibre was coated with a coating solution of dimethylpolysiloxane by dip-coating technique. The coating solution was achieved by dissolving dimethylpolysiloxane available from Aldrich (DMPSV) in $0.1 \%$ of dichloromethane (Lab Scan Analytical Sciences). After the deposition process, the optical fibre was cured at $70.0^{\circ} \mathrm{C}$ during $24 \mathrm{~h}$. Finally, the sensitized optical fibre was placed inside a $7.0 \mathrm{~cm}$ long glass tube (analytical tube) in form of T. The experimental set-up is further constituted by an injection cell (glass cell), where VOCs were injected with a gastight micro syringe (Hamilton). The injection cell was maintained at $80.0^{\circ} \mathrm{C}$ inside an isothermal chamber, using a coiled tape heater available from Cole Parmer. The organic compounds were injected as liquids, and after vaporization the organics were carried by a continuous flow of reagent grade nitrogen Paxair (carrier gas) controlled by a flowmeter (Sigma). All reagents used were analytical grade and were used without further purification.

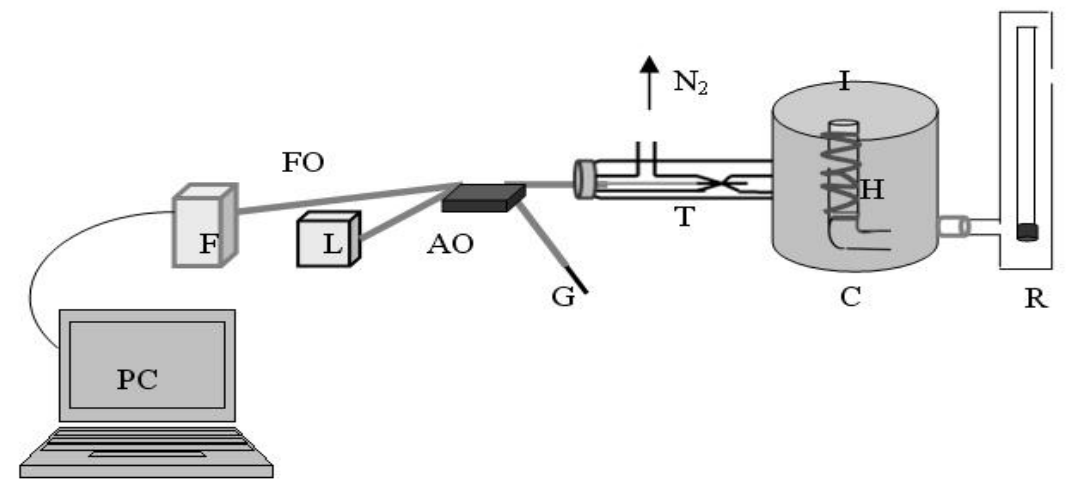

Figure 1. Schematic configuration of the experimental layout

( $\mathrm{I}$ - injection cell, C- isothermal chamber, $\mathrm{R}$ - flowmeter, $\mathrm{T}$ - glass tube, AO - optical coupler, $\mathrm{L}$ - laser diode, F - photodetector, FO - optical fibre, G - index matching liquid, $\mathrm{H}$ - tape heater, PC - laptop containing home made software) 


\section{Sampling details}

Sampling took place in a Portuguese solvent industry, performed according to NIOSH 1501 method (NIOSH, 2003e) for ethylbenzene and xylene, 1500 method ( $\mathrm{NIOSH}, 2003 \mathrm{c}$ ) for heptane and octane, 1003 method (NIOSH, 2003d) for chloroform and carbon tetrachloride, 1400 method (NIOSH, 2003a) for ethanol and 1405 method (NIOSH, 2003b) for butanol, using coconut shell charcoal, $100 \mathrm{mg} / 50 \mathrm{mg}$ (Supelco Cat no. 20267-U).

\section{RESULTS AND DISCUSSION}

Figures $2 \mathrm{a}$ and $2 \mathrm{~b}$ show the sensor response after injection of different amounts of ethylbenzene and xylene, respectively.

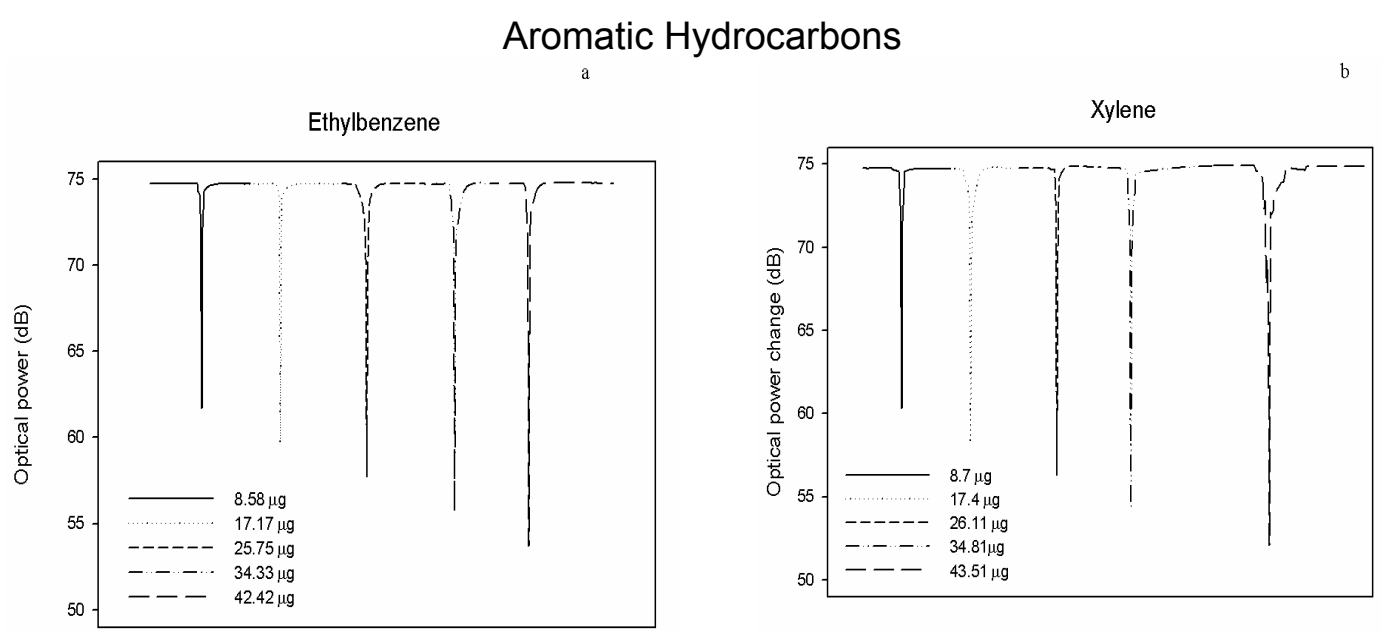

Figure 2. Sensor response for injections of two aromatic hydrocarbons, namely ethylbenzene and xylene

A variation of $23 \mathrm{~dB}$ of the optical power on $43.51 \mu \mathrm{g}$ of xylene analysis, as observed in Figure $2 \mathrm{~b}$ indicates a high detection capability of the sensor system. The analytical response (response and recovery time) obtained with the newly sensor is very short, approximately 30 seconds, which constitute an excellent analytical advantage. Figures $3 \mathrm{a}$ and $3 \mathrm{~b}$ report the calibration curves obtained for the two aromatic hydrocarbons (ethylbenzene and xylene) analysed.
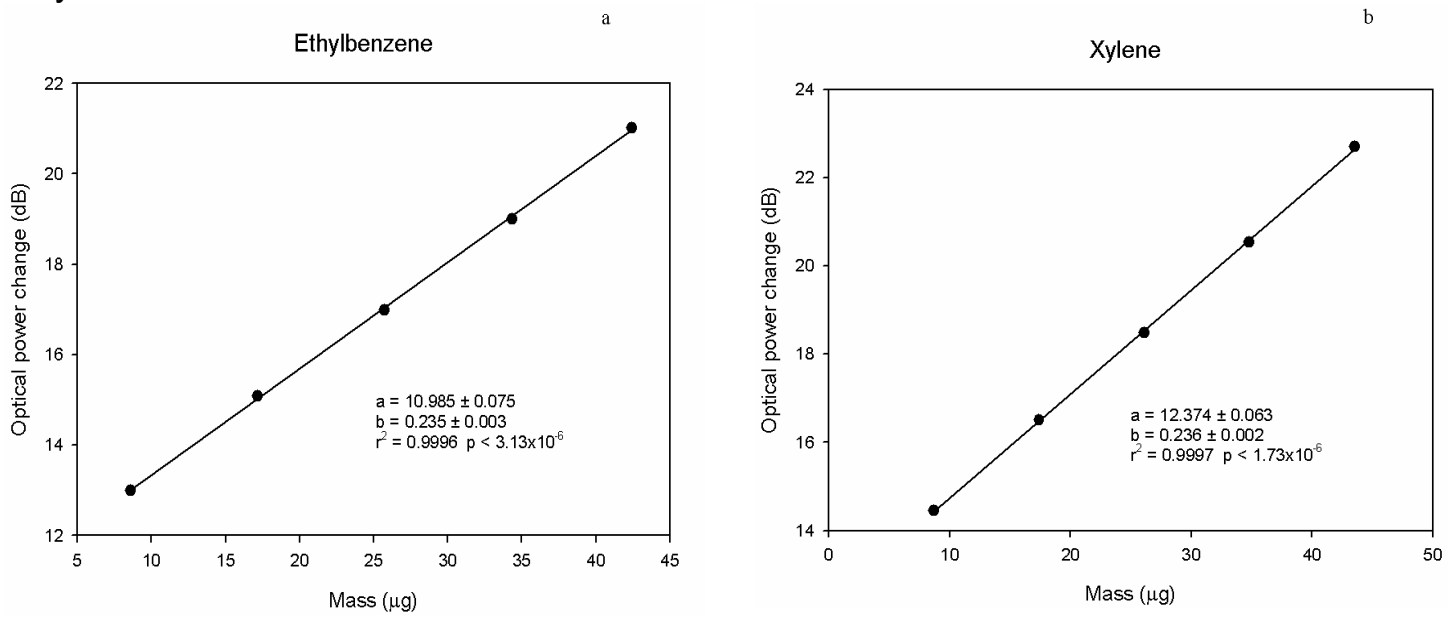

Figure 3. Calibration curve obtained with sensor system for injections of two aromatic hydrocarbons; a. calibration curve obtained for ethylbenzene, and, b. calibration curve obtained for xylene.

The experimental device shows excellent linearity for both aromatic hydrocarbons detected (ethylbenzene and xylene), as shown in Figure 3. The calibration model used was $y=a+b x$ 
and the analytical sensitivity (slope of the calibration curve) obtained for the two aromatic hydrocarbons analysed was very similar. However the analytical response (optical power change) obtained during xylene detection was lightly higher (approximately $1.5 \mathrm{~dB}$ ) than the one obtained for ethylbenzene, these facts could be explained taking into account that these compounds have the same molecular mass but a different value of the boiling temperature, namely $136.2^{\circ} \mathrm{C}$ for ethylbenzene and $144.4^{\circ} \mathrm{C}$ for xylene and different vapour pressure (10 and $7 \mathrm{mmHg}$ at $20^{\circ} \mathrm{C}$ for ethylbenzene and xylene, respectively).

Figure 4 shows a set of profiles of optical power changes obtained with increasing injection amounts $(6.5$ and $35 \mu \mathrm{g})$ of heptane and octane. The analytical signal (optical power change) obtained for octane was approximately three times higher than the one obtained for heptane. In terms of the analytical sensitivity the sensor shows also higher sensitivity for octane analysis, as it could be observed in Figure $5 \mathrm{a}$, which reports the calibration curves obtained for heptane and octane. From the obtained results (displayed in Figures 4 and $5 \mathrm{a}$ ) it is possible to infer that the analytical signal and sensitivity of the developed sensor increase as the boiling temperature of the analyte increase $\left(98^{\circ} \mathrm{C}\right.$ for heptane $<125-127^{\circ} \mathrm{C}$ for octane) and decrease of vapour pressure in $\mathrm{mmHg}$ at $20^{\circ} \mathrm{C}$ (40 for heptane $>11$ for octane). This sensor system behaviour, that is, the increase of the analytical sensitivity with the increase of the boiling temperature of the analytes was also observed by Abdelmalek et al. during the analytical response evaluation of an optical fibre polymer based sensor for organic vapour detection (Abdelmalek et al., 1999).

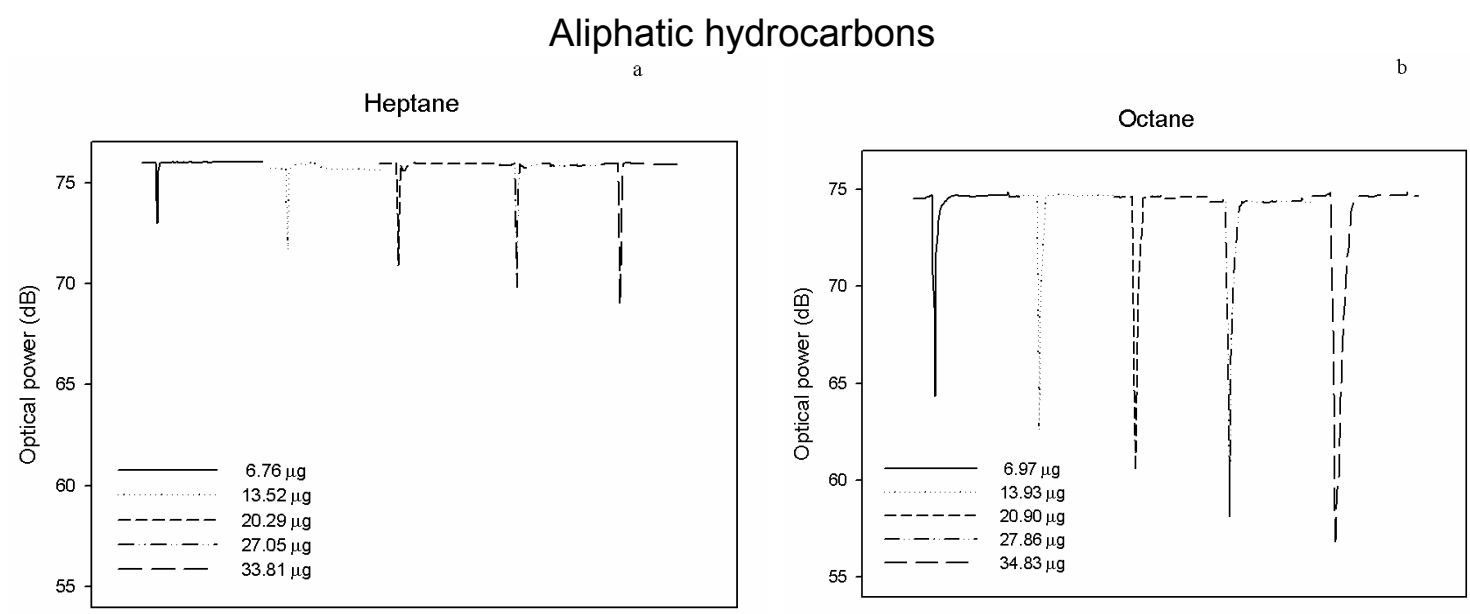

Figure 4. Sensor response for injections of two aliphatic hydrocarbons, a. sensor response obtained for heptane in a range between 6.76 and $33.81 \mu \mathrm{g}$, and, b. sensor response obtained for octane in a range between 6.97 and $34.83 \mu \mathrm{g}$.

Figures $5 \mathrm{a}$ and $5 \mathrm{~b}$ show the calibration curves obtained for two aliphatic hydrocarbons (heptane and octane) and two chlorinated hydrocarbons (chloroform and carbon tetrachloride), respectively

Figure 6 (a. and b.) shows the sensor response after injections of different amounts of chloroform and carbon tetrachloride. The newly sensor system exhibit adequate analytical performance for chlorinated hydrocarbons monitoring, with optical power changes between 1 and $8 \mathrm{~dB}$, during chloroform and carbon tetrachloride analysis. The developed sensor shows different sensitivity for the two chlorinated hydrocarbons, as it could be observed in Figure $5 \mathrm{~b}$. The sensitivity is higher for carbon tetrachloride, which has higher boiling temperature (76-77 ${ }^{\circ} \mathrm{C}$ ) and lower vapour pressure $\left(91 \mathrm{mmHg}\right.$ at $20^{\circ} \mathrm{C}$ ) than chloroform (boiling temperature of $60.5-61.5{ }^{\circ} \mathrm{C}$ and vapour pressure in $\mathrm{mmHg}$ at $20^{\circ} \mathrm{C}$ of 160 ), being these results in good agreement with the results obtained for aromatic and aliphatic hydrocarbons detection. 
Aliphatic hydrocarbons

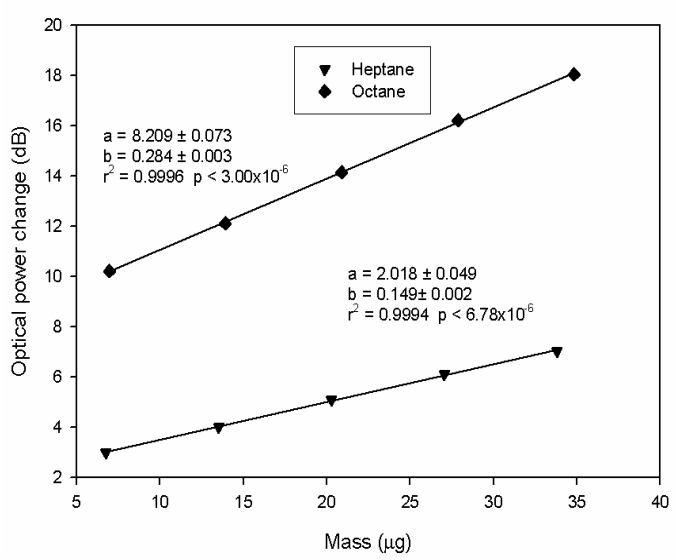

Chlorinated Hydrocarbons

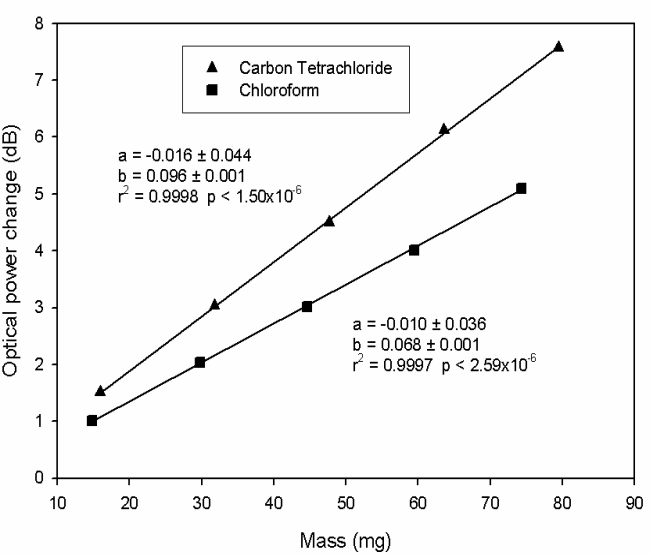

Figure 5. Calibration curve obtained with sensor system for injections of two aliphatic and chlorinated hydrocarbons; a. calibration curve obtained for heptane and octane, b. calibration curve for chloroform and carbon tetrachloride

Chlorinated hydrocarbons
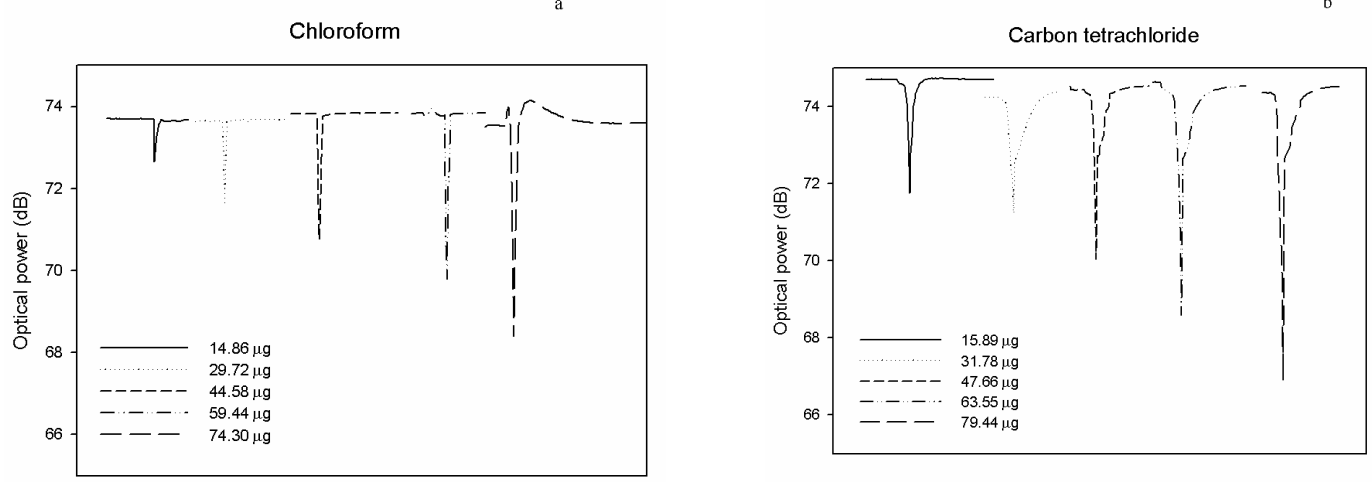

Figure 6. Sensor response for injections of different amounts of two chlorinated hydrocarbons, a. sensor response obtained for chloroform in a range between 14.86 and $74.30 \mu \mathrm{g}$, and, $\mathrm{b}$. sensor response obtained for carbon tetrachloride in a range between 15.89 and $79.44 \mu \mathrm{g}$

Alcohols
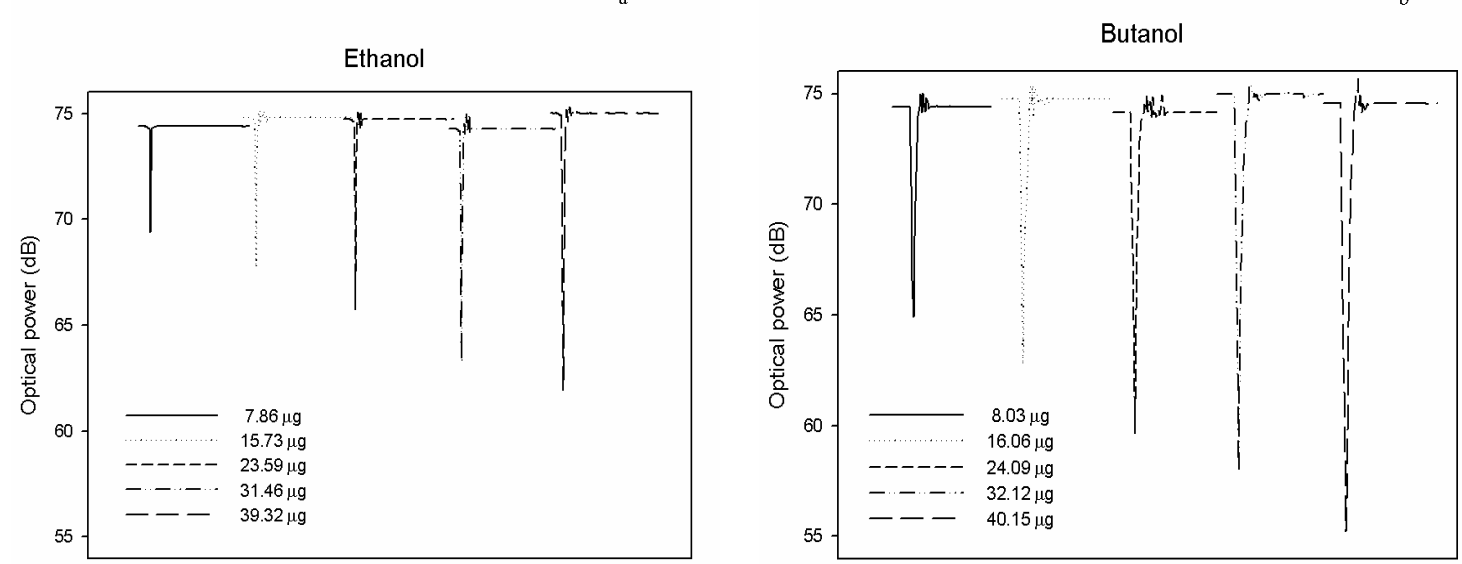

Figure 7. Sensor response for alcohols analysis (a. sensor response after injection of ethanol in a range between 7.86 and $39.32 \mu \mathrm{g}$; b. sensor response after injection of butanol in a range between 8.03 and $40.15 \mu \mathrm{g}$ ) 
The analytical performance of the developed sensor system was also evaluated for alcohols; the obtained results are shown in Figure 7 (a. and b.) which reports the sensor response for different amounts of two alcohols, ethanol and butanol.

Changes up to $19 \mathrm{~dB}$ were detected during butanol analysis, indicating the high potential of the developed sensor for alcohols monitoring.

Figure 8 shows the potential for calibration of the sensor response for alcohols (ethanol and butanol) monitoring. The proportional increase on optical power change with the increase of the different injected amounts of both ethanol and butanol, allows to conclude about the linearity of the sensor in the range of 7.86 to $39.32 \mu \mathrm{g}$ and 8.03 to $40.15 \mu \mathrm{g}$ for ethanol and butanol, respectively.

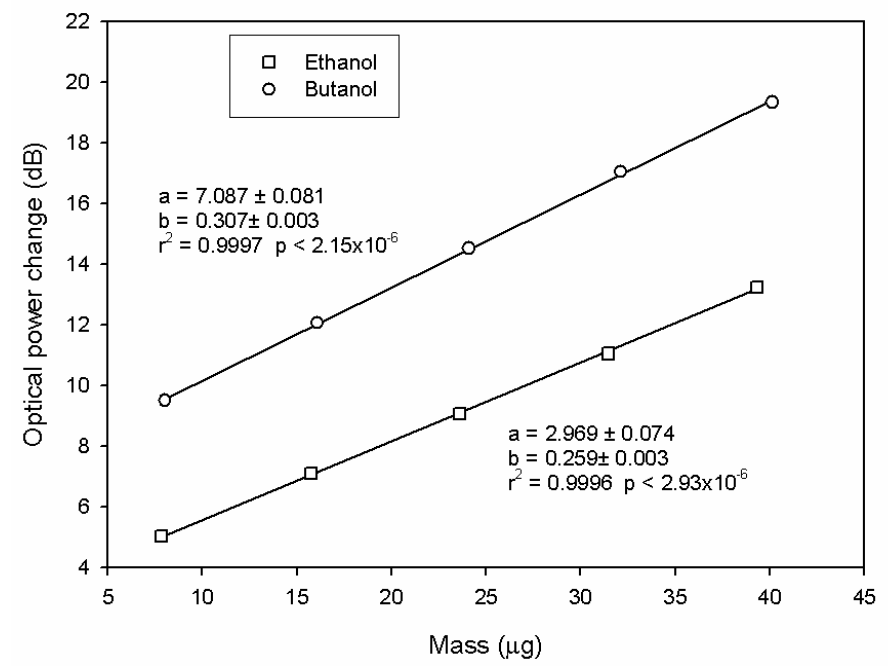

Figure 8. Calibration curve obtained with sensor system for injections of ethanol and butanol

The analytical sensitivity obtained for alcohols detection was higher (specifically for butanol analysis) than the one obtained for the others classes of VOCs studied (aromatic, aliphatic and chlorinated hydrocarbons), a possible explanation can be performed taking into account the interactions which can take place between the analyte molecule and the sensitive film. It is important to highlight that the sensor sensitivity depends either on the analyte molecule and sensitive film proprieties, which has an important role concerning the analytical performance of the optical fibre sensor.

The detection limits based on 3 times the residual standard deviation, obtained for the eight VOCs compounds analysed were, respectively, $0.91 \mu \mathrm{g}$ for ethylbenzene, $0.76 \mu \mathrm{g}$ for xylene, $0.93 \mu \mathrm{g}$ for heptane, $0.73 \mu \mathrm{g}$ for octane, $1.81 \mu \mathrm{g}$ for chloroform,1.33 $\mathrm{\mu g}$ for carbon tetrachloride, $0.82 \mu \mathrm{g}$ for ethanol and $0.76 \mu \mathrm{g}$ for butanol, respectively.

Taking into consideration all the above experimental results it is possible to infer that the developed sensor system shows high analytical performance for different classes of VOCs monitoring, namely, aromatic hydrocarbons (ethylbenzene and xylene), aliphatic hydrocarbons (heptane and octane), chlorinated hydrocarbons (carbon tetrachloride and chloroform) and alcohols (ethanol and butanol).

The analytical performance of the developed sensor was also evaluated concerning reproducibility. Table 1 shows the results (using ethanol as example), in terms of optical power variation for injections of $15.73 \mu \mathrm{g}$ of ethanol with the same sensor, on consecutive weeks.

An ANOVA was applied for statistic analysis of the obtained results and no statistically difference were found between weeks $(\alpha=0.05)$ for the eight VOCs analysed. The residual variability (residual mean squares) was estimated as approximately $6.4 \times 10^{-4}, 4.5 \times 10^{-4}, 6.2 \times 10^{-}$ $5,3.3 \times 10^{-5}, 8.8 \times 10^{-5}, 9.7 \times 10^{-5}, 2.8 \times 10^{-5}, 3.0 \times 10^{-6}$ for ethylbenzene, xylene, heptane, octane, chloroform, carbon tetrachloride, ethanol and butanol, respectively. The between-weeks 
variability was not significantly $(p=0.172,0.144,0.210,0.070,0.271,0.338,0.259$ and 0.452 for ethylbenzene, xylene, heptane, octane, chloroform, carbon tetrachloride, ethanol and butanol, respectively) higher than residual variability. Therefore the sensor response was shown to be stable over the time and no increase in variability was observed when analytical work was performed in different weeks.

Table 1. Optical power changes obtained in consecutive weeks, with five injections of $15.73 \mu \mathrm{g}$ of ethanol, for the same sensor

\begin{tabular}{|l|r|r|r|r|}
\hline \multirow{2}{*}{ Ethanol $(\mu \mathrm{g})$} & \multicolumn{4}{|c|}{ Optical power variation $(\mathrm{dB})$} \\
\cline { 2 - 5 } & \multicolumn{1}{|c|}{ st week } & $2^{\text {nd }}$ week & \multicolumn{1}{l|}{$3^{\text {rd }}$ week } & \multicolumn{1}{l|}{${ }^{\text {th }}$ week } \\
\hline \multirow{3}{*}{15.73} & 7.029 & 7.038 & 7.034 & 7.037 \\
\cline { 2 - 5 } & 7.036 & 7.023 & 7.034 & 7.026 \\
\cline { 2 - 5 } & 7.021 & 7.025 & 7.033 & 7.035 \\
\cline { 2 - 5 } & 7.023 & 7.036 & 7.032 & 7.037 \\
\cline { 2 - 5 } & 7.025 & 7.023 & 7.032 & 7.028 \\
\hline Mean & 7.027 & 7.029 & 7.033 & 7.032 \\
\hline Standard deviation & 0.006 & 0.007 & 0.001 & 0.005 \\
\hline
\end{tabular}

The analytical sensor response repeatability (Caulcutt, 1983) was estimated $9.8 \times 10^{-2}, 8.7 \times 10^{-2}$, as $2.9 \times 10^{-2}, 2.8 \times 10^{-2}, 3.1 \times 10^{-2}, 3.0 \times 10^{-2}, 1.8 \times 10^{-2}$ and $5.0 \times 10^{-3}$ for ethylbenzene, xylene, heptane, octane, chloroform, carbon tetrachloride, ethanol and butanol, respectively. The reproducibility is in this case coincident with the repeatability since between weeks variability is not significant.

As a final remark no variations in optical power signal were observed after one month of constant operation with this sensor system, indicating high analytical system stability.

The developed analytical system was also applied to five actual samples collected in a Portuguese solvent industry and the obtained results are displayed in Table 2.

Table 2. Sensor results for five actual samples of confined atmosphere from a Portuguese solvent industry

\begin{tabular}{|l|c|c|c|c|c|}
\hline & \multicolumn{5}{|c|}{ Concentration $\left(\mu \mathrm{g} \mathrm{I}^{-1}\right)$} \\
\cline { 2 - 6 } & Sample 1 & Sample 2 & Sample 3 & Sample 4 & Sample 5 \\
\hline Ethylbenzene & $3.418 \pm 0.026$ & $3.385 \pm 0.015$ & $3.570 \pm 0.012$ & $3.336 \pm 0.019$ & $3.383 \pm 0.036$ \\
\hline Xylene & $1.724 \pm 0.026$ & $1.691 \pm 0.015$ & $1.875 \pm 0.012$ & $1.642 \pm 0.019$ & $1.689 \pm 0.036$ \\
\hline Heptane & $1.624 \pm 0.047$ & $1.803 \pm 0.042$ & $1.524 \pm 0.037$ & $1.320 \pm 0.053$ & $1.274 \pm 0.057$ \\
\hline Octane & $1.760 \pm 0.035$ & $1.809 \pm 0.016$ & $1.913 \pm 0.023$ & $1.886 \pm 0.014$ & $1.566 \pm 0.032$ \\
\hline Chloroform & $5.888 \pm 0.090$ & $5.775 \pm 0.050$ & $6.412 \pm 0.040$ & $5.607 \pm 0.067$ & $5.767 \pm 0.123$ \\
\hline Carbon tetrachloride & $9.492 \pm 0.064$ & $9.411 \pm 0.036$ & $9.866 \pm 0.029$ & $9.291 \pm 0.048$ & $9.406 \pm 0.088$ \\
\hline Ethanol & $39.419 \pm 0.117$ & $39.170 \pm 0.101$ & $39.910 \pm 0.077$ & $39.874 \pm 0.142$ & $40.217 \pm 0.160$ \\
\hline Butanol & $6.410 \pm 0.021$ & $6.460 \pm 0.018$ & $6.503 \pm 0.005$ & $6.410 \pm 0.009$ & $6.573 \pm 0.016$ \\
\hline
\end{tabular}

The obtained results for the eight VOCs analysed (ethylbenzene, xylene, heptane, octane, chloroform, carbon tetrachloride, ethanol and butanol) are lower than the occupational exposure limits recommend by NIOSH: $4.34 \mathrm{mg} \mathrm{m}^{-3}$ for ethylbenzene and xylene (NIOSH, $2003 \mathrm{e}$ ), $4.10 \mathrm{mg} \mathrm{m}^{-3}$ for heptane (NIOSH, 2003c), $4.67 \mathrm{mg} \mathrm{m}^{-3}$ for octane (NIOSH, 2003c), $9.78 \mathrm{mg} \mathrm{m}^{-3}$ for chloroform (NIOSH, 2005a), $12.6 \mathrm{mg} \mathrm{m}^{-3}$ for carbon tetrachloride (NIOSH, 2005b), $1900 \mathrm{mg} \mathrm{m}^{-3}$ for ethanol (NIOSH, 2005c) and $305 \mathrm{mg} \mathrm{m}^{-3}$ for butanol (NIOSH, 2005d).

\section{CONCLUSIONS}

A compact chemical optical fibre sensor coated with a siloxane polymer has been developed for monitoring some different classes of VOCs. The newly developed sensor shows a high analytical stability, linearity, repeatability, reproducibility and analytical sensitivity for ethylbenzene, xylene, heptane, octane, chloroform, carbon tetrachloride, ethanol and butanol 
detection. Furthermore, this sensor exhibit high potential for continuous monitoring at the industrial environment and it could contribute for the development of appropriate control strategies of VOCs emissions.

\section{ACKNOWLEDGMENTS}

This work has been developed under the scope of the FCT (Portugal) funded research project POCTI/CTA/44899/02: "Development of a new Optical Fiber Chemical Sensor for in-situ monitoring of VOCs (VOCSENSOR)" and a PhD grant (SFRH / BD / 17288 / 2004) awarded to Lurdes I. B. Silva is also gratefully acknowledged.

\section{REFERENCES}

Abdelghani A., Chovelon J.M., Jaffrezic-Renault N., Veilla C. and Gagnaire H., (1997a), Chemical vapour sensing by surface plasmon resonance optical fibre sensor coated with fluoropolymer, Analytica Chimica Acta, 337, 225-232.

Abdelghani A., Chovelon J.M., Jaffrezic-Renault N., Lacroix M., Gagnaire H., Veillas C., Berkova B., Chomat M. and Matejec V., (1997b), Optical fibre sensor coated with porous silica layers for gas and chemical vapour detection, Sensors and Actuators B, 44, 495-498.

Abdelghani A. and Jaffrezic-Renault N. (2001), SPR fibre sensor sensitised by fluorosiloxane polymers, Sensors and Actuators B, 74, 117-123.

Abdelmalek F., Chovelon J.M., Lacroix M., Jaffrezic-Renault N. and Matejec V., (1999), Optical fibre sensors sensitized by phenyl-modified porous silica prepared by sol-gel, Sensors and Actuators B, 56, 234-242.

Bariáin C., Matías I., Romeo I., Garrido J. and Laguna M., (2001), Behavioral experimental studies of a material towards development of optical fibre organic compounds sensor, Sensors and Actuators B, 76, 25-31.

Bariáin C., Matías I.R., Fernández-Valdivielso C., Arregui F.I., Rodrígues-Méndez M.L. and Saja J.A., (2003), Optical fiber sensor based on lutetium bisphthalocyanine for the detection of gases using standard telecommunication wavelengths, Sensors and Actuators B, 93, 153158.

Bariáin C., Matías I.R., Fdez-Valdivielso C., Elosúa C., Luquin A., Garrido J. and Laguna M., (2005), Optical fiber sensors based on vapochromic gold complexes for environmental applications, Sensors and Actuators B, 108, 535-541.

Campbell M. (1997), Sensor systems for environmental monitoring, Vol.1, Blackie Academic \& Professional, London.

Caulcutt R. and Boddy R., (1983), Statistic for Analytical Chemists, Chapman and Hall Ltd, London.

Dubray A. and Vanderschuren J., (2004), Mass transfer phenomena during sorption of hydrophilic volatile organic compounds into aqueous suspensions of activated carbon, Separation and purification Technology, 38, 215-223.

Elosúa C., Bariáin C., Matías I.R., Arregui F.J., Luquin A. and Laguna M., (2006), Volatile alcoholic compounds fibre optic nanosensor, Sensors and Actuators B, 115, 444-449.

EPA, Indoor Air Quality, Sources of Indoor Air Pollution - Organic Gases (Volatile Organic Compounds - VOCs) (2007): http://www.epa.gov/iaq/voc.html (accessed on December 4, 2007).

Horrillo M.C., Fernández M.J., Fontecha J.L., Sayago I., García M., Aleixandre M., Santos J.P., Arés L., Gutiérrez J., Gràcia L. and Cané C., (2004), Detection of volatile organic compounds using surface acoustic wave sensors with different polymer coatings, Thin Solid Films, 467, 234-238.

Kondratowicz B., Narayanaswamy R.and Persuad K.C., (2001), An investigation into the use of electronic polymers in optical fibre gas sensors, Sensors and Actuators B, 74, 138-144.

$\mathrm{NIOSH}$ Manual of Analytical Methods (NMAM) (2003a), Alcohols I: Method 1400, Fourth Edition, Issue 3, DHHS (NIOSH) Publication, Washington D.C.

$\mathrm{NIOSH}$ Manual of Analytical Methods (NMAM) (2003b), Alcohols Combined: Method 1405, Fourth Edition, Issue 3, DHHS (NIOSH) Publication, Washington D.C.

$\mathrm{NIOSH}$ Manual of Analytical Methods (NMAM) (2003c), BP $36^{\circ}-216^{\circ} \mathrm{C}$ Hydrocarbons: Method 1500, Fourth Edition, Issue 3, DHHS (NIOSH) Publication, Washington D.C. 
NIOSH Manual of Analytical Methods (NMAM) (2003d), Halogenated hydrocarbons: Method 1003 Fourth Edition, Issue 3, DHHS (NIOSH) Publication, Washington D.C.

NIOSH Manual of Analytical Methods (NMAM) (2003e), Hydrocarbons aromatic: Method 1501, Fourth Edition, Issue 3, DHHS (NIOSH) Publication, Washington D.C.

NIOSH Pocket Guide to Chemical Hazards (2005a): http://www.cdc.gov/niosh/npg/npgd

0127.html (accessed on December 4, 2007).

NIOSH Pocket Guide to Chemical Hazards (2005b): http://www.cdc.gov/niosh/npg/npgd 0107.html (accessed on December 4, 2007).

NIOSH Pocket Guide to Chemical Hazards (2005c): http://www.cdc.gov/niosh/npg/npgd 0262.html (accessed on December 4, 2007).

NIOSH Pocket Guide to Chemical Hazards (2005d): http://www.cdc.gov/niosh/npg/npgd

0076.html (accessed on December 4, 2007).

Turner N., Jones M., Grice K., Dawson D., loppolo-Armanios M. and Fisher S.J. (2006) $\delta^{13} \mathrm{C}$ of volatile organic compounds (VOCs) in airborne samples by thermal desorption-gas chromatography-isotope ratio-mass spectrometry (TD-GC-IR-MS), Atmospheric Environment, 40, 3381-3388.

Zimmermann B., Bürck J. and Ache H.-J. (1997), Studies on siloxane polymers for NIRevanescent wave absorvance sensors, Sensors and Actuators $B, 41,45-54$. 